\title{
Effect of Soil Strength and Soil Physical Properties on Performance of Tillage Machines
}

\author{
Mehrez Bashar, Yang Zhou and li Jun \\ College of Engineering, South China Agricultural University, Guangzhou 510000, Guangdong, China
}

Received: March 10, 2015 / Accepted: March 25, 2015 / Published: April 25, 2015.

\begin{abstract}
Soil parameters have significant influence on the performance of tillage machines for various kinds of tillage operations, such as soil movement by tillage tool, soil cutting, soil turning, soil pulverization, and manure injections, etc. This paper attempts to provide a clear overview of soil physical properties and soil strength, and their effects on the performance of tillage machines. Furthermore; it includes the descriptions and characteristics of these parameters, and last developed equipment and procedure for evaluating and assessing of these parameters.
\end{abstract}

Key words: Tillage machines; soil cutting; soil turning; soil pulverizing.

\section{Introduction}

Tests of various soil tillage machinery aim at studying the behavior of these machines from the point of view of their dynamic and energetic performances and of the quality of work. Up to date there is no precise definition of the quality of the work. For instance, quality of the work can be evaluated by clod size, the evenness of the operative depth and percentage of plant residue covered after a tillage operation [1]. Soil physical properties and soil shear strength have significant influence on the performance of tillage machinery, this is because of the interaction between these properties and tillage tool energy requirement.

This article aims to review the previous studies related to the effect of soil physical properties and soil shear strength on the performance of tillage machines and it will provide good understanding of these factors.

\section{Effect of Soil Physical Properties}

Soil moisture content and soil texture affect mechanical behavior and strength of soil. Soils at

Corresponding author: Yang Zhou, professor, research field: agricultural machinery. E-mail: yangzhou@scau.edu.cn. same mechanical and environmental conditions but different texture behave differently. Camp and Gill [2] and Smith [3] reported that shear strength parameters of fine grained soils decreased with increasing moisture content. However, the soil density was concurrently decreasing as the moisture content was increased. Presence of water in void space of fine- grained soils can have a major impact on the engineering behavior of the soil. Therefore, it is important to know not only how much water is present, but also how it can affect engineering behaviors. As moisture content of a soil increases, the soil changes from a brittle solid to a plastic solid and eventually to a viscous liquid. These limits along with the natural moisture content are paramount in predicting the behavior of fine-grained soils. The limits can be correlated to the engineering soil properties such as strength, compressibility, swelling potential, and stress history. Rashidi et al. [4] mentioned that SMC (soil moisture content), TD (tillage depth) significantly $(P \leq 0.01)$ affected draft force of moldboard plow.

Bulk density of a soil is a function of soil moisture at any given amount of compactive effort. As the soil wetness increases, the moisture weakens the inter-particle bonds, causing swelling and reducing 
internal friction making the soil more workable and compactable [5]. However, as the soil wetness nears saturation, the fractional volume of expellable air is reduced and the soil can no longer be compacted to the same degree as before with the same compactive effort. The optimum moisture content is the point at which the soil wetness is just enough to expel all the air from the soil, and the corresponding density is the maximum dry density. Mouazen and Ramon [6] reported that draft force of subsoil was increased with wet and dry bulk densities where it decreased with soil moisture content. Draft force was changed linearly with moisture content where it was a quadratic function of wet bulk density and a cubic function of dry bulk density respectively. The decrease in draft with moisture content did not extend beyond a moisture content of $17 \%$.

Mechanical behavior of soil is influenced by any changes that occur in soil bulk density [7]. This normally happens during tillage operations. Ayers [8] studied the effect of soil moisture content and density effect on soil shear strength parameters of coarse grained soils during tillage operations. It was reported that cohesion and friction angle of those three loamy sand soils employed in the study increased with increasing soil density. Tillage treatments are expected to affect soil response and crop yield. Erbach et al. [9] evaluated the effect of no till; chisel plow, moldboard plow, and par plow systems on three types of soil (poorly drained, medium, and fine textured). Results showed that all tillage tools reduced bulk density and penetration resistance to the depth of operation. However, after planting, only the soil tilled with the par plow remained less dense than before the tillage.

\section{Effect of Soil Shear Strength}

The strength of a soil is its ability or capacity at a particular condition, to resist or endure an applied load. The strength of soil to be tilled maybe described by evaluating the parameters involved in the soil's yield conditions on application of a load. In tillage, soil yielding or soil failure is achieved through a combination of tillage and traction forces. The combined force system can cause the soil to fail or yield by shear, compression, tension and/or plastic flow [10].

Yield in agricultural soil can be approximated using the Mohr-Coulomb failure criterion. The criterion postulates that the failure occurs when the maximum shear strength of the given materials. Gill and Vanden Berg [11] traced the history of the original coulomb theory from its postulation to straight line failure envelope of the Mohr failure theory. The failure envelope is expressed as:

$$
\tau_{\max }=C_{C}+\sigma_{n} \tan \phi
$$

whereas:

$\tau_{\max }$ : Maximum shearing stress at failure (kpa)

$C_{C}$ : Soil cohesion (kpa)

$\sigma_{n}$ : Normal stress (kpa)

$\phi$ : Angle of internal friction of the soil (deg)

In classical soil mechanics, Eq. (1) is referred to as the Mohr-coulomb equation. This equation represents shear failure at a point within a soil mass. Therefore, the criterion of shear failure using this expression must be carefully distinguished from the distribution of shear point failures, the shear plane or surface.

The application of this equation is limited to effective stress cases and does not apply when the total stresses are considered [12].

Gill and Vanden Berg [11] referring to Eq. (1) stated that: While the straight line envelope of Mohr theory does not rigorously represent shear yield in all soil conditions, the theory has been close enough so the extent that this equation has, almost universally, been accepted as a low. One confusing factor is the fact that $C_{c}$ and one confusing factor is the fact that $C_{c}$ and $\phi$ are so firmly entrenched that they are often referred to as real physical properties of the soil. In reality they are only of the assumed yield equation; and their logical existence can be explained only by an interpretation of the equation, and not from the physical nature of the soil itself. 
Taking into consideration Eq. (1), it is evident that the magnitude of the soil shear strength depends on the soil-soil friction and soil cohesion. The soil cohesion parameter $\left(C_{c}\right)$ represents the maximum shear stress value of the soil when the normal stress is equal to zero. The cohesion parameter depends only on the strength of the in situ bonds between soil particles. Therefore, $C_{C}$ is constant, irrespective of the magnitude of the normal stress applied to the body of the soil. The shear stress associated with soil-soil friction, on the other hand, results from the sliding of soil over soil, and is therefore directly influenced by the magnitude of the normal load. Stafford and Tanner [13] reported a linear relationship between the maximum shear strength and the normalstress applied. Both of cohesion $\left(C_{C}\right)$ and the coefficient of internal friction $(\tan \phi)$ are influenced by soil water content, porosity and grain size distribution of the soil material. In general, $C_{C}$ and $\tan \phi$ increase with decrease in porosity whereas cohesion at any given density, increases with soil water content reaching a maximum at some intermediate level and decreasing thereafter as the soil water content increases. Although a similar observation was made by Wells and Treesuwan [14].

A study by Kuipers and Kroesbergen [15] indicated a decrease of the cohesion value with increasing soil water content, this disagreement in the behavior of soil cohesion could be due to the difference in ranges of the soil water content levels studied by respective researcher. In addition, it is probable that the textures of the soil studied by these researchers were different resulting in the reported differences in the variation of the soil cohesion with the soil content. In general soil cohesion increases with the soil water content, reaching a peak value and therefore, decreases with further increases in soil water content. The magnitude of this variation is affected by the soil texture and the soil bulk density.

\section{Assessing of Soil Properties}

Soil water content can be measured by using the standard oven drying procedure $[16,17]$. The soil samples for determination of the water content must be collected immediately upon the completion of test-run. At least ten soil samples of about $40 \mathrm{~g}$ have to be collected in metallic containers from different locations and different depths. The mass of the collected moist soil samples will be determined using a scale balance with good accuracy. The samples must be placed in the oven at $105{ }^{\circ} \mathrm{C}$ for at least 24 hours as described by Bardet [16]. In addition to this way many soil moister sensors have been developed recently for providing quick measurement of soil moisture. For instance, TZS-1K soil moisture sensor shown in Fig. 1, this sensor can provide a corresponding values of soil moisture for different locations and different depths.

Determination of soil textural classification can be done by using standard sieve method Bardet [16] Textural classification will be done by collection adequate soil samples randomly from designated experimental site and using the UDSA soil classification system [18]. In this method, soil textures are classified by the fractions of each soil separate (sand, silt, and clay) present in a soil. Classifications are typically named for the primary constituent particle size or a combination of the most abundant particles sizes, e.g. "sandy clay" or "silty clay". A fourth term, loam, is used to describe a roughly equal concentration of sand, silt, and clay, and lends to the

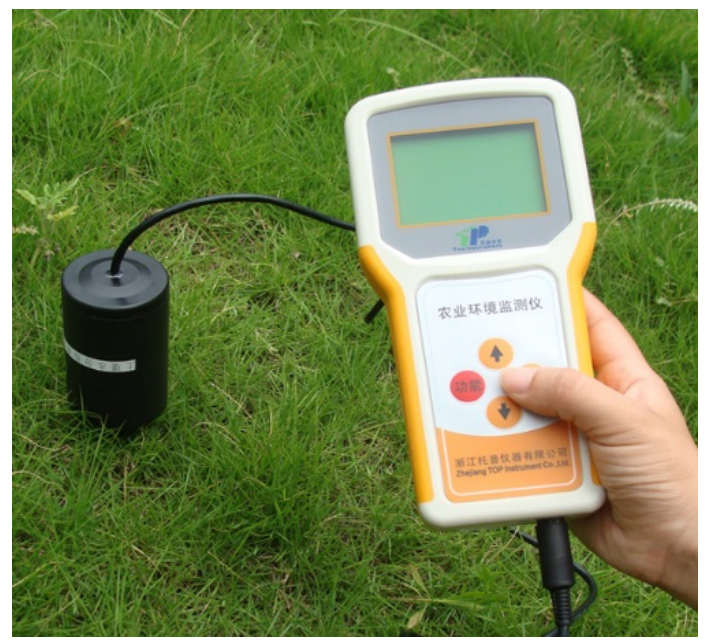

Fig. 1 TZS-1Ksoil moisture sensor. 
naming of even more classifications, e.g. "clay loam" or "silt loam". Several laboratory and in situ measurement methods and devices of soil shear strength parameters have been introduced in soil mechanics books.

Among field measurement devices, the following devices have been widely used by the researchers: annular shear ring, shear graph, rectangular plate, shear vane, cone penetrometer, and pocket penetrometer. Many researchers have preferred laboratory measurement tests like triaxial test and direct shear test. Both of these methods will be described briefly in next subsection.

Triaxial test, as the first shear strength test able to measure pore-water pressure of soil during shear strength measurement, is still valid and very common although other tests with similar features have been developed. Results of this test can be individually used to predict the behavior and characteristics of the soil, or they can be used to measure other characteristics of the soil such as consolidation and permeability characteristics. During the test, principle stresses as well as drainage can be controlled and pore water pressure is measured. During a tillage operation sometimes soil undergoes a shearing at a high rate. To obtain soil parameters for such a dynamic situation, it is required to perform a high speed triaxial test on same soil sample in which soil experiences load at similar rates as it would encounter during the real tillage operation.

Direct shear test is an inexpensive, fast, and simple way to determine shear strength characteristics, especially those of granular materials. This test is conducted by placing a soil sample into a shear box similar to Fig. 2 that is split with the bottom half fixed and the top half free to float. A loading block with a porous stone to allow drainage of water is placed on the sample, a normal load is applied and the loading block and top half of the box are clamped together allowing the two halves to separate slightly.

Shear box test is used to determine the angle of internal friction of a soil. As the horizontal displacement increases the shear force along the predetermined slip-plane also increases due to one half of the soil being restrained. Eventually, the soil reaches a maximum or peak shear stress and after the peak, the shear resistance decreases and failure occurs. Multiple tests are needed to determine the angle of internal friction. If soil-metal friction angle is desired, it can be measured by placing a plate made of the same metal as tool's metal between two halves of the apparatus during the test.

\section{Conclusion}

Soil strength and soil physical properties have great influence on performance of agricultural machinery,

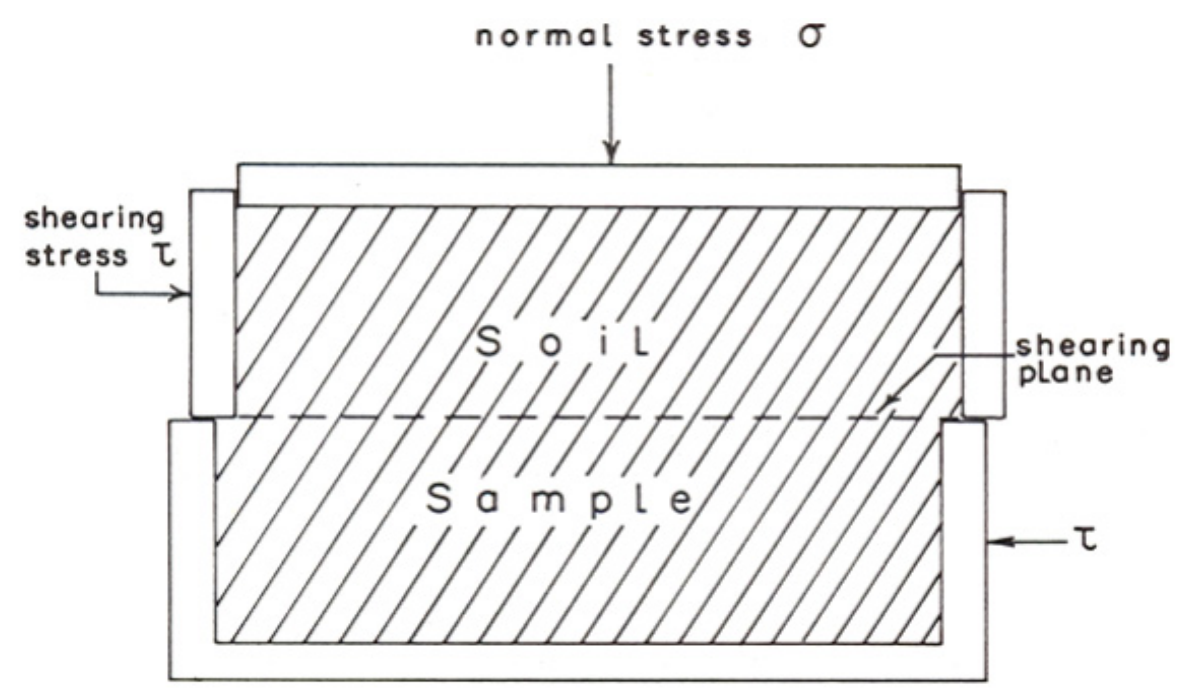

Fig. 2 Direct Shear Apparatus (from Hillel 1980). 
and these parameters must be taken into consideration in any research aim to evaluate and study various kinds of agricultural machines. Soil moisture content influences soil failure mechanism machines greatly. Soil moisture content also has a great influence on other soil parameters, this interaction between soil moisture content and other soil parameters is not fully understood, but most of researchers have reported that increasing moisture content will affect in decreasing of shear strength parameters. The soil density was concurrently decreasing also as the moisture content was increased. As result, pertinent soil parameters must be monitored for the quantification of tillage performance including the soil water content, soil bulk density, soil shear strength and the soil metal friction parameters. There is also a need for a simple field method to determine soil strength in a way that is useful for predictions of draught and power requirement.

\section{Acknowledgements}

This work was supported by Science and Technology Planning Project of Guangdong (2013B020501002), Foundation for High-level Talents in Higher Education of Guangdong (Guangdong finance education [2011] No. 431), China Spark Program (2013GA780042).

\section{References}

[1] Srivastava, A. K., Goering, C. E., and Rohrbach, R. P. 1993. "Engineering Principles of Agricultural Machines." American Society of Agricultural Engineers Book, No. 6. American Society of Agricultural Engineers 2950 Nile road, St. Joseph, Michigan, USA.

[2] Camp, D. R., and Gill, W. R. 1969. "The Effect of Drying on Soil Strength Parameters." Soil Science Society of America Proceedings 13 (5): 641-4.

[3] Smith, J. L. 1964. "Strength-Moisture-Density Relations of Fine Grained Soils in Vehicle Mobility Research." Technical report No. 3-369. U.S. Army Engineer Waterways Experimental Station. Vicksburg, MS.

[4] Rashidi, M., Najjarzadeh, I., Jaberinasab, B., Emadi, S. M., and Fayyazi, M. 2013. "Effect of Soil Moisture
Content, Tillage Depth and Operation Speed on Draft Force of Moldboard Plow." Middle-East Journal of Scientific Research 16 (2): 245-9.

[5] Hillel, D. 1980. Fundamentals of Soil Physics. 1st edition. New York, NY: Academic Press, Inc.

[6] Mouazen, A. M., and Ramon, H. 2002. "A Numerical Hybrid Modelling Scheme for Evaluation of Draught Requirements of A Subsoiler Cutting A Sandy Loam Soil, As Affected by Moisture Content, Bulk Density, and Depth." Soil \& Tillage Research 63: 155-65.

[7] Gitau, A. N., Gumbe, L. O., and Biamah E. K. 2006. "Influence of Soil Water on Stress Strain Behavior of a Compacting Soil in Semi-Arid Kenya." Soil and Tillage Res. 89: 144-54.

[8] Ayers, P. D. 1987. "Moisture and Density Effect on Soil Shear Strength Parameters for Coarse Grained Soils." Transactions of the ASAE 30 (5): 1282-7.

[9] Erbach, D. C., Benjamin, J. G., Cruser, R. M., Elamin, M. A., Mukhtar, S., and Choi, C. H. 1992. "Soil and Corn Response to Tillage with Para Plow." Transactions of the ASAE 35 (5): 1347-54.

[10] Johnson, C. E., Grisso, R. D., Nichols, T. A., and Bailey, A. C. 1987. "Shear Measurement for Agricultural Soils-A Review." Transactions of the ASAE 30 (4): 935-8.

[11] Gill, W. R., and Vanden Berg, G. E. 1968. Soil Dynamics in Tillage and Traction. USDA-ARS Agricultural Handbook No. 316. U.S., Washington DC 20402: Government Printing Office.

[12] Chancellor, W. J. 1994. "Soil Physical Properties." In Advances in Soil Dynamics, edited by Hansen, P. D. St. Joseph, MI: ASAE, St. Joseph, MI: ASAE.

[13] Stafford, J. V., and Tanner, D. W. 1983. "Effect of Rate on Soil Shear Strength and Soil-Metal Friction, I. Shear Strength." Soil \& Tillage Research 3: 245-61.

[14] Wells, L. G., and O. Treesuwan. 1978. "The Response of Soil Strength Indices to Changing Water Content and Bulk Density." Transactions of the ASAE, 854-61.

[15] Kuiper, H., and Kroesbergen, B. 1966. "The Significance of Moisture Content, Pore Space, Method of Sample Preparation and Type of Shear Annulus on Laboratory Torsional Shear Testing of Soils." Journal of Terramechanics 3 (4): 17-28.

[16] Bardet, J. 1997. Experimental Soil Mechanics. Prentice Hall. ISBN: 0133749355.

[17] Mandal, J. N., and Divshikar, D. G. 1994. Soil Testing in Civil Engineering. India Book House Limited. ISBN: 8120409035.

[18] McKyes, E. 1989. “Agricultural Engineering Soil Mechanics." Developments in Agricultural Engineering 10. Elsevier Publishing. 